\title{
A construção de um canteiro econômico na Escola Estadual do Povoado de Nova Aurora (Norte Mineiro) no contexto de um projeto de intervenção do Estágio Supervisionado IV do curso de Licenciatura em Educação do Campo da UFTM
}

The construction of an economic site in the state school of the people of Nova Aurora (north Minas Gerais) in the context of a project for intervention of the supervised internship IV of the licensing course in education in the field of

UFTM

Graciene Ferreira de Oliveira Rodrigo dos Santos Crepalde Verônica Klepka

Resumo: O canteiro econômico é uma tecnologia social que demanda uma pequena quantidade de água para a produção de alimentos. Assim, configura-se como uma estratégia importante de convivência com a seca, especialmente em regiões como o semiárido Norte Mineiro. Este trabalho busca apresentar e discutir a experiência de construção de um canteiro econômico em uma escola do campo no contexto de um projeto de intervenção do Estágio Supervisionado IV do curso de Licenciatura em Educação do Campo da UFTM. Adotamos a pesquisa qualitativa e como fonte de dados lançamos mão do relatório final do estágio, bem como informações provenientes de entrevistas semiestruturadas com a professora supervisora, direção e outros trabalhadores da escola. A construção do canteiro econômico mobiliza conhecimentos como o uso de adubos orgânicos, da lona plástica como um impermeabilizante, a economia de água, entre outros. Introduziu-se a partir das aulas de Ciências uma novidade, a tecnologia social do canteiro de tipo econômico, ao mesmo tempo, que os conteúdos das Ciências eram contextualizados na prática. Por fim, essa experiência de Estágio Supervisionado IV mostra uma possibilidade de integração dos conhecimentos das Ciências e os conhecimentos da comunidade, dos agricultores em uma prática coerente e contextualizada com a vida no/do campo.

Palavras-chave: Canteiro econômico. Convivência com a seca. Estágio supervisionado. Ensino de Ciências. Educação do Campo.

\begin{abstract}
The economic construction site is a social technology that requires a small amount of water for food production. Thus, it is an important strategy for dealing with drought, especially in regions such as the northern semiarid region. This paper seeks to present and discuss the experience of building an economic construction site in a rural school in the context of an intervention project of the Supervised Internship IV of the UFTM field education course. We adopted qualitative research and as a source of data, we used the final report of the internship, as well as information from semi-structured interviews with the supervising teacher, management and other school workers. The construction of the economic construction site mobilizes knowledge such as the use of organic fertilizers, plastic canvas as a waterproofing agent, water savings, among others. A novelty was introduced from the Science classes, the social technology of the economic type construction site, at the same time, that the contents of the Sciences were
\end{abstract}


contextualized in practice. Finally, this Supervised Internship IV experience shows a possibility of integrating the knowledge of the Sciences and the knowledge of the community, of farmers in a coherent and contextualized practice with life in / from the countryside.

Keywords: Economic construction site. Living with drought. Supervised internship. Science Teaching. Rural Education.

\section{Introdução}

O acesso e disponibilidade de água e a convivência com a seca sempre foram pontos decisivos para a sobrevivência e existência dos povos do Cerrado que estão no Norte Mineiro. A chegada da monocultura de eucalipto na região, a partir da década de 1970, trouxe um suposto "desenvolvimento". Inicialmente, os moradores acreditavam ser um bom empreendimento para as comunidades, geração de empregos e renda para o sustento. Logo começaram a derrubar o bioma dando lugar ao "reflorestamento" com eucaliptos e em paralelo surgiram as carvoarias. A cada ano que passava, percebia-se que os frutos do Cerrado e as nascentes estavam desaparecendo. Além disso, práticas tradicionais como o extrativismo e o cultivo de variedades de arroz, feijão, milho, dentre outros foram sendo abandonadas: a terra já não era mais a mesma.

As terras que deram lugar ao eucalipto eram tidas como comuns por seus moradores, mas foram "repassadas" pelo Estado à grandes empresas "reflorestadoras".

Em primeiro lugar, é preciso dizer que essas terras devolutas, simbolicamente arrendadas pelo Estado, se constituíam de terras de uso comum das comunidades sertanejas que faziam uso dessas chapadas através do extrativismo dos frutos do Cerrado para uso alimentar [...], medicinal [...] produção de óleo e sabão [...]. As comunidades também soltavam o gado para pastar nesses cerrados nas épocas de maior restrição de forragem dos pastos plantados. Foi, portanto, um processo de privatização de terras públicas de uso comum dessas comunidades. (SILVA; PORTO-GONÇALVES, 2004, p. 1).

Os moradores dessas comunidades foram encurralados pela monocultura e já não tinham como colher os frutos do Cerrado, ou soltar seus animais. Viramse obrigados a sair de suas propriedades para trabalhar fora da comunidade como na colheita do café no Sul de Minas e em outras regiões. Até os dias de 
hoje, deixam suas comunidades por cerca de três meses, até por mais tempo, para trabalhar e depois retornam para suas moradias. Como as famílias saem completas para estes trabalhos fora da comunidade, acabam que os filhos deles que estavam em idade escolar, também são prejudicados nos estudos e/ou nem voltam mais a estudar.

Desde o final da década de 1990, houve um despertar das comunidades Geraizeiras, povos tradicionais do Cerrado, frente a essa monocultura na região, juntamente com as comunidades mais atingidas, foram em busca de seus direitos com o objetivo de procurar a reapropriação dessas terras, que na verdade eram territórios onde estes geraizeiros viviam em harmonia com a natureza e podiam cuidar de suas famílias.

A reapropriação territorial de comunidades geraizeiras atingidas pela monocultura de eucalipto acontece por parte da "quebra" da dormência de uma resistência velada, mas que se transforma numa resiliência reivindicatória se multiplicando nas comunidades da microrregião que reconheceram possibilidades e capacidades de agir. A possibilidade de reconquista das terras após um período de grande escassez e das consequências que essa traz, estimula um pensar a terra de um modo diferenciado. A terra, a água e o Cerrado passam a ser ainda mais valorizados do que eram no período pré-eucalipto associado a um valor simbólico que tem a natureza de uma forma geral para a vida tradicional local. Ao constatarem que algumas nascentes estavam revivendo nos lugares onde o eucalipto cessara, e ante os resultados das primeiras investidas organizadas que visou o restabelecimento das nascentes, outras comunidades se contagiaram com a ideia de retomada do território e aderiram a rede de geraizeiros em defesa de seu território (BRITO, 2012, p. 347).

Diante desse cenário, tomou forma a proposta de construção de um canteiro econômico para a intervenção em Estágio Supervisionado IV, pela primeira autora, então licencianda em Educação do Campo, área do conhecimento Ciências da Natureza e insider de uma comunidade do campo do Norte Mineiro.

O canteiro econômico "é uma tecnologia social que utiliza uma pequena quantidade de água para a produção de hortaliças - a principal diferença entre eles e os canteiros tradicionais é o volume de água que se utiliza para manter as produções" (SEMEAR INTERNACIONAL, 2019, p. 1). 
O diferencial desse canteiro é que a água não se perde por infiltração, devido à impermeabilização, mas apenas por evapotranspiração. As famílias gastam menos água para produzir num canteiro comparado ao convencional, pois a água fica acumulada em baixo, simulando um micro lençol freático. (LEITE et al., 2017, p. 36-37).

Muito se discute sobre a necessidade de desenvolver práticas que visem à preservação do meio ambiente. Partindo deste ponto, a implantação do canteiro econômico corresponde a um instrumento pedagógico com o objetivo principal da formação de alunos participativos e o incentivo ao desenvolvimento de práticas que visem à preservação do meio ambiente e o consumo de alimentos orgânicos e saudáveis.

O tema da escassez de água é uma das grandes preocupações dos moradores de comunidades do campo na região Norte do estado de Minas Gerais, apesar disso, geralmente, não é abordado em sala de aula. Os temas escolares muitas vezes estão longe da realidade dos alunos e por não fazerem referência à exemplos vividos por eles, muitos alunos não se sentem como partes complementares do meio ambiente em que vivem (AMARAL et al., 2009).

Por sua vez, a Educação do Campo compreende um movimento pedagógico que não fica restrito ao ambiente da escola, ela assume que para educar de modo coerente com a vida no/do campo é preciso partir das vivências daqueles que vivem da terra, dos seus saberes, das suas histórias e memórias, das suas lutas e das suas identidades (CALDART, 2011).

A perspectiva do estágio em forma de projetos assume-se como potencialidade de produzir conhecimento sobre algo real, concreto, respondendo também às demandas da escola. Trata-se de unir a questão educativa com o trabalho conjunto, por meio dos quais haja coautores e não apenas executores. Parte da identificação de demandas da escola e de seu entorno e visa uma tomada de posição, ao mesmo tempo em que reflete uma concepção de sociedade (PIMENTA; LIMA, 2012).

Nesse contexto é que apresentamos e discutimos neste artigo a experiência de construção de um canteiro econômico em uma escola do campo no contexto de um projeto de intervenção do Estágio Supervisionado IV do curso 
de Licenciatura em Educação do Campo (LECampo) da Universidade Federal do Triângulo Mineiro (UFTM).

\section{Do estágio à pesquisa: contexto, projeto de intervenção e percursos metodológicos}

Em um primeiro momento, apresentamos aos leitores o contexto do Estágio IV na LECampo-UFTM, na sequência o contexto da escola do Povoado de Nova Aurora e a comunidade camponesa em que está inserida. A primeira autora deste trabalho estudou nessa escola e é uma moradora do campo, portanto, essa reflexão carrega a experiência de alguém de dentro, uma insider, no sentido de alguém que fala a partir do campo e que passou por seu processo de escolarização no ambiente da pesquisa e que desloca-se como pesquisadora para compreender a própria realidade e suas vivências. Posteriormente expomos uma síntese da intervenção com a temática do canteiro econômico na Escola do Povoado de Nova Aurora realizada durante as aulas de Ciências da Natureza do $7^{\circ}$ ano do Ensino Fundamental. Por fim, situamos o estágio em articulação com a pesquisa realizada, caracterizando sua natureza e sujeitos.

\section{O ESTÁGIO IV NA LECAMPO DA UFTM}

No curso de Licenciatura em Educação do Campo da UFTM, o Estágio Supervisionado Obrigatório possui para cada uma das áreas de conhecimento (Ciências da Natureza e Matemática) um total de 480 horas, divididas em quatro semestres, a partir do $5^{\circ}$ período do curso. Em cada estágio uma especificidade formativa é trabalhada. O Estágio I objetiva o mapeamento da instituição educacional na qual o estágio será realizado ao longo dos semestres seguintes, caracterizando-a socio-demograficamente e pedagogicamente. O Estágio II visa a realização de observação e regência nos anos finais do Ensino Fundamental II, enquanto no Estágio III a observação e a regência ocorrem nos três anos do Ensino Médio. Para os estudantes da habilitação em Ciências da Natureza esse processo se repete em cada componente curricular: Física, Química e Biologia.

No contexto do Estágio IV, foco das reflexões aqui trazidas, cabe a elaboração e execução de um Projeto Educativo no campo de estágio. No caso das turmas de Ciências da Natureza, 30 horas teóricas são utilizadas em sala de 
aula na Universidade para a construção individual de projetos de intervenção escolar sob constante orientação da professora da disciplina. A disciplina iniciase com a discussão, resgate e levantamento de problemáticas e/ou necessidades verificadas na escola que acolheu cada um dos estudantes nos semestres anteriores, e, preferencialmente das turmas com as quais trabalhou ligadas ao conteúdo de Ciências da Natureza ou ainda questões que nascem de saberes ou práticas culturais da comunidade em que se localiza a escola passíveis de articulação com os conhecimentos escolares das ciências (UFTM, 2019).

Constatadas as demandas ou possibilidades temáticas, cabe ao aluno sob orientação docente, elaborar um projeto educacional sobre o tema escolhido. As aulas seguintes são utilizadas, uma a uma, para construção: i) dos objetivos que se espera alcançar com o projeto; ii) do levantamento na literatura de trabalhos similares e das lacunas de pesquisa; III) da metodologia de intervenção, discriminação da etapa de ensino e adequação dos conteúdos escolares e populares ao tema escolhido; iv) de um instrumento avaliativo da intervenção e do aprendizado alcançado pelo público-alvo; e, v) do título e da apresentação da proposta e relevância para o contexto a ser aplicado. Formato bastante similar a um projeto de pesquisa acadêmica (OVIGLI; KLEPKA, 2020).

Nos últimos anos, temáticas decorrentes de questões da realidade local, de conhecimentos e saberes culturalmente produzidos por comunidades do campo emergentes em atividades de ensino, projetos de pesquisa, entre outros, passaram a aparecer em propostas/projetos de intervenção no Estágio Supervisionado IV como um retorno à realidade e, por vezes, como problematização desta no âmbito escolar. Foi o caso da temática abordada neste artigo, a problemática da falta d'água, especificamente no povoado de Nova Aurora - Rio Pardo de Minas, compôs-se de objeto de estudo advindo majoritariamente de própria realidade do campo da primeira autora, especificidade observada também na continuidade de seu processo formativo, 0 que a fez levar a mesmo objeto do estágio para sua pesquisa de trabalho de conclusão de curso (TCC). 
Em seu caráter educativo, o estágio é o exercício da docência e como tal também deve ser intencional, mobilizando os conhecimentos específicos, interdisciplinares e pedagógicos "que se desenvolvem entre conhecimentos científicos e culturais, [...] no diálogo constante entre diferentes visões de mundo" (RESOLUÇÃO CNE n. 2/07/2015, p. 2).

A realidade concreta dos sujeitos que d[á] vida ao currículo e às instituições de educação básica [...] os projetos de formação devem ser contextualizados no espaço e no tempo [...] bem como possibilitar a reflexão sobre as relações entre a vida, o conhecimento, a cultura, o profissional do magistério, o estudante e a instituição" (RESOLUÇÃO CNE n. 2/07/2015, p. 2).

O que reflete o fato das problemáticas trazidas de suas comunidades de origem pelos próprios licenciandos e que passaram a ser integrados nas atividades de estágio supervisionado obrigatório IV e até mesmo em seus TCCs. Essa integração resgata como premissa a noção de quais conteúdos devem ser reconhecidos e integrados às aulas de ciências, numa perspectiva intercultural:

[...] do nosso ponto de vista, aqueles conhecimentos relacionados às práticas sociais desenvolvidas pelos educandos e/ou suas comunidades que favoreçam mutuamente 0 desenvolvimento de conceitos científicos. No nosso contexto, da formação de professores de ciências para o campo, podemos elencar temas passíveis dessa integração: sementes crioulas, biofertilizantes, repelentes naturais, relação das plantas com as culturas e sociedade, segurança alimentar, práticas de cuidado, uso do solo, artefatos tecnológicos do campo, dentre outros que relacionam-se às identidades ligadas à vida no/do campo (CREPALDE et al., 2019, p. 281).

Diferentemente do que se observa na literatura (ASSAI; BROIETTI; ARRUDA, 2018), no curso de Licenciatura em Educação do Campo da UFTM, o estágio IV não pressupõe unicamente tratar de questões inerentes do estágio ou do campo pedagógico ou ainda de conteúdos das ciências. Por outro lado, exibe a inclusão de temas nascidos de realidades do campo, locais de vivência dos próprios licenciandos (OVIGLI; KLEPKA, 2020).

\section{O contexto da intervenção: povoado de Nova Aurora e escola}


O povoado de Nova Aurora é uma das cerca de 90 comunidades rurais do município de Rio Pardo de Minas, no Norte do estado de Minas Gerais cuja população estimada para 2019 era de 30.914 pessoas (IBGE, 2020). O clima da região é semiárido, bioma de transição entre Cerrado e Caatinga, apresentando também aspectos de Mata Atlântica.

Nova Aurora é uma comunidade do campo, onde as famílias cultivam lavouras tais como cana de açúcar, mandioca, feijões, milho, abóbora, batata doce, amendoim, café sombreado, também criam aves e suínos nos quintais de suas casas. Os jovens, adolescentes e crianças de Nova Aurora estudam na escola do povoado. Quando os jovens terminam o Ensino Médio, fazem o mesmo de outros familiares, saem da comunidade em busca de emprego, muitos vão migrar temporariamente para a safra de café no Sul de minas, outros já se deslocam para morar na sede do município de Rio Pardo de Minas. Os mais idosos têm suas rendas vindas de aposentadorias.

A comunidade de Nova Aurora possui 150 residências com uma população de cerca de 600 habitantes. Nova Aurora também é conhecida por chapada, porque o terreno é plano e alto, com altitude acima de 600 metros, está localizada a $50 \mathrm{~km}$ da sede do município.

Quanto à questão da água no Povoado de Nova Aurora, em seu entorno existiam pequenas nascentes: Cabeceira, Veredinha, Biquinha, além de uma fonte de água usada no consumo das famílias da comunidade e na criação de animais. No início do Povoado era tempo de muita chuva quando se comparado com os dias de hoje. Mas para conseguir um balde de água potável era preciso buscar e carregar no ombro, andando uma distância de 2 a $4 \mathrm{~km}$. No decorrer dos anos, as nascentes foram secando gradativamente e as famílias crescendo. Para amenizar o problema, foi aberto um poço manual (cacimba ${ }^{1}$ ), a uma profundidade média de dez metros. A água era retirada puxando-se com uma corda fixa um balde de 20 litros. Além do enorme risco de acidente, o poço foi baixando o volume de água, tornando impossível a retirada e mesmo secando totalmente. Anos depois fizeram um reservatório de água na nascente da

\footnotetext{
${ }^{1}$ Cacimba é um buraco cavado na terra para atingir o lençol freático em busca de água.
} 
Cabeceira, com auxílio de um motor a óleo diesel que ajudava no abastecimento de água para comunidade, atualmente passou a ser movida a eletricidade.

Com a população aumentando, apesar de tanto esforço, a água ainda não era o suficiente para atender toda a demanda. Nem todas as famílias têm chance de receber água em casa em decorrência também da necessidade de correção do nível da canalização. O abastecimento de água atual conta com ajuda de caminhão pipa, uma vez na semana ou quando algum morador pede para trazer água para sua casa. Quando falta o carro pipa, alguns locais do povoado têm os chamados chafarizes, são torneiras instaladas em calçadas que, às vezes, são a única alternativa de água no povoado, onde os moradores levam carriolas com baldes, vasilhas e tambores para carregar água. Como na escola existe um poço, então na frente dela há uma torneira na parede do muro para utilização pela comunidade (Figura 1).

Figura 1 - Moradores da Comunidade de Nova Aurora com suas carriolas para pegar água na torneira montada no muro da escola.

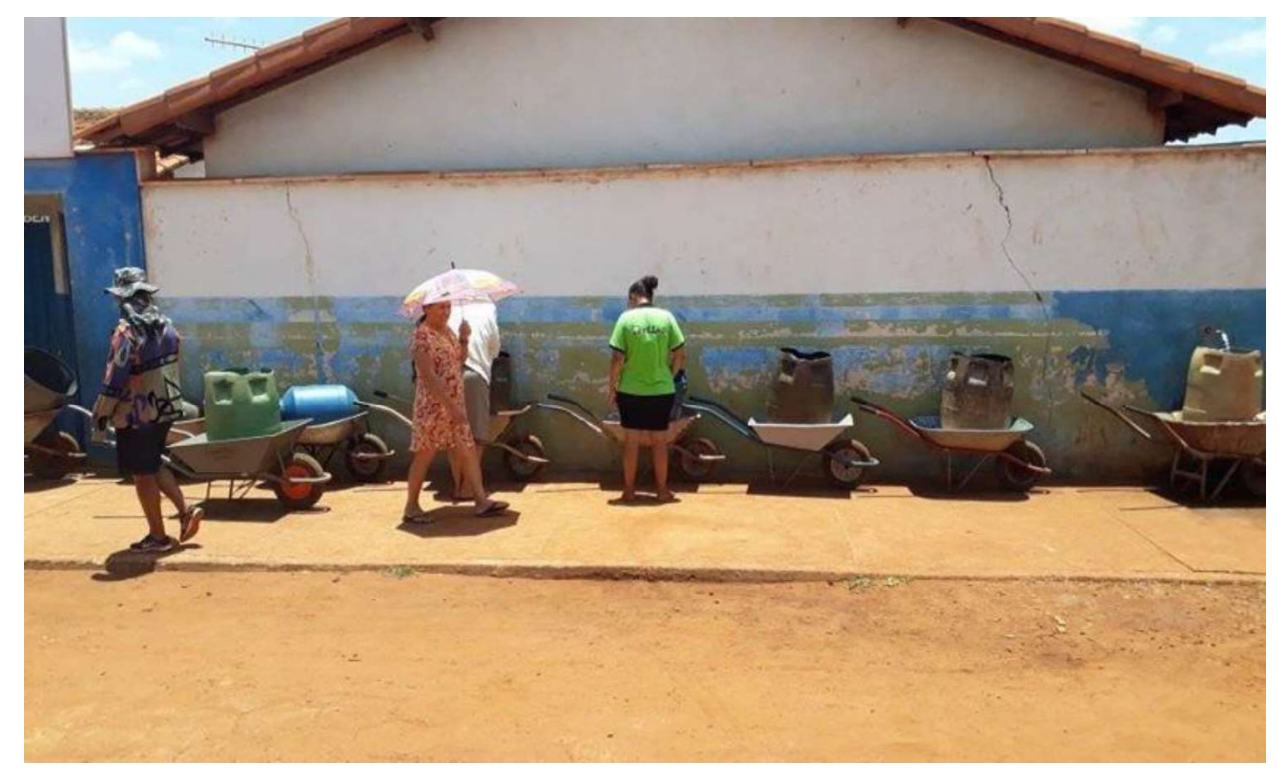

Fonte: Folha Regional (2019).

A Escola Estadual do Povoado de Nova Aurora começou a funcionar no ano de 1982, atendendo a alunos de $1^{\circ}$ ao $5^{\circ}$ ano do Ensino Fundamental. Em 2008, passa a oferecer também o Ensino Médio. Atualmente atende desde a primeira etapa do Ensino Fundamental até o Ensino Médio. Possui 12 turmas, em média 325 alunos por ano oriundos de comunidades vizinhas tais como: 
Peixe Bravo, Pindaíba, Rocinha, Aurora, Simão Guedes, Vista Alegre, Terra Quebrada, Gênio, Curralinho, Monte Alegre e Prata, localizadas no município de Rio Pardo de Minas, e do próprio Povoado de Nova Aurora.

A Escola Estadual do Povoado de Nova Aurora tem como espaço físico uma área de $1500 \mathrm{~m}^{2}$ e este terreno é dividido em 10 salas de aula, 2 banheiros sanitários, uma sala para secretaria, uma cantina e uma biblioteca. Observamos que falta área de lazer para os alunos e professores, laboratórios, não há refeitório, os alunos comem em pé nas salas ou nas calçadas da escola, entre outras estruturas que uma escola necessita para um melhor funcionamento. Os professores e zeladores que trabalham na escola são todos concursados, habilitados e designados para os cargos de atuação, a maioria deles reside fora da sede escolar.

O deslocamento de aproximadamente 300 alunos das comunidades do entorno escolar é feito por meio de seis ônibus e um micro-ônibus. Muitas das vezes, esse transporte escolar é precário e não oferece condições de segurança aos estudantes. Em alguns veículos nem sequer existe o cinto de segurança. As estradas estão em condições péssimas, esburacadas e poeirentas. Quando chega o tempo das chuvas, muitos dos alunos faltam às aulas, visto que as estradas ficam intransitáveis pelo fato de haver muita lama e até mesmo os carros ficarem atolados.

\section{O projeto de intervenção}

Conforme discutem Pimenta e Lima (2012, p. 228), "o estágio com pequenos projetos possibilita que os estagiários vivenciem um processo em todas as suas etapas de diagnóstico, planejamento, execução e avaliação [...]".

São nas aulas teóricas (Tempo Escola) da disciplina que todo planejamento do projeto é realizado. Já em Tempo Comunidade, a carga horária prática inicia-se com o contato com diretor da escola e a professora supervisora momento em que foi explicado cada passo do projeto do canteiro econômico. Discutimos juntos a possibilidade de inserir a proposta de estágio nas aulas de Ciências e ficou combinado que iríamos ter como foco o $7^{\circ}$ ano do Ensino Fundamental. Nessa conversa, justificamos que o projeto poderia abordar 
conceitos da Educação Ambiental na escola, a importância de uma alimentação saudável, o incentivo ao consumo de produtos orgânicos e o desenvolvimento de práticas agroecológicas. A proposta foi bem recebida, uma vez que ela dialoga com o contexto da escola e das suas comunidades atendidas.

As atividades do projeto ocorreram com uma turma do $7^{\circ}$ ano do Ensino Fundamental II da Escola do Povoado de Nova Aurora, composta por 11 meninas e 19 meninos, com a faixa etária entre 12 e 13 anos. As aulas foram desenvolvidas entre os meses de abril e maio do ano de 2019. De modo síntese, expomos no quadro abaixo (Quadro 1) as principais informações da intervenção construída no Estágio Supervisionado IV.

Quadro 1: Síntese da intervenção do Estágio Supervisionado IV

\begin{tabular}{|c|c|c|}
\hline Tema & & Canteiro econômico \\
\hline Objetivos & Geral & $\begin{array}{l}\text { Investigar os conhecimentos dos alunos sobre o } \\
\text { contexto da água e a produção de alimentos no } \\
\text { Povoado de Nova Aurora, para montar canteiro } \\
\text { econômico na escola Estadual Povoado de Nova } \\
\text { Aurora. }\end{array}$ \\
\hline & Específicos & $\begin{array}{l}\text { - Compreender a falta de água na comunidade de } \\
\text { Nova Aurora e como é o abastecimento até chegar às } \\
\text { residências desta comunidade; } \\
\text { - Analisar os conhecimentos prévios dos alunos e } \\
\text { incluir este no ensino em sala de aula; } \\
\text { - Discutir meios de uso e conservação da água; } \\
\text { - Comparar o uso da água em um canteiro econômico } \\
\text { e em um convencional (qual seria a melhor opção para } \\
\text { a comunidade?). }\end{array}$ \\
\hline Metodologia & \multicolumn{2}{|c|}{ Aula expositiva dialogada, atividade prática e roda de conversa. } \\
\hline \multirow{4}{*}{$\begin{array}{l}\text { Distribuição } \\
\text { das aulas } \\
\text { ( } 5 \text { aulas de } \\
50 \text { min } \\
\text { distribuídas } \\
\text { em } 2 \\
\text { semanas) }\end{array}$} & Aulas & Conteúdos e ações \\
\hline & $1^{\mathrm{a}}$ & $\begin{array}{l}\text { Apresentação, discussão e preparação inicial "canteiro } \\
\text { econômico". }\end{array}$ \\
\hline & $2^{\mathrm{a}}$ & $\begin{array}{l}\text { Uso e conservação da água; ciclo da água; alimentação } \\
\text { saudável; uso de adubos orgânicos e sobre os riscos de } \\
\text { se usar agrotóxicos nas lavouras. }\end{array}$ \\
\hline & $3^{a}$ & $\begin{array}{l}\text { Levantamento dos legumes e hortaliças que são } \\
\text { cultivados nas comunidades e escolha daqueles que } \\
\text { serão plantados no canteiro econômico. }\end{array}$ \\
\hline
\end{tabular}




\begin{tabular}{|l|l|l|}
\hline \multirow{2}{*}{} & $4^{\mathrm{a}}$ & $\begin{array}{l}\text { Construção do canteiro econômico e distribuição da } \\
\text { tarefa da sua manutenção (grupo de } 3 \text { alunos em } \\
\text { revezamento). }\end{array}$ \\
\cline { 2 - 3 } & $5^{\mathrm{a}}$ & $\begin{array}{l}\text { Discussão sobre os principais conceitos abordados e } \\
\text { avaliação sobre o processo de construção do canteiro } \\
\text { econômico. }\end{array}$ \\
\hline Avaliação & \multicolumn{2}{|l|}{ Produção escrita individual sobre a temática desenvolvida. } \\
\hline
\end{tabular}

Fonte: Elaborado pelos autores.

Após o contato com a escola, deu-se início as atividades do projeto (Quadro 1), e na $4^{a}$ aula, a construção do canteiro econômico. Conforme um morador e agricultor de Pindaíba, uma das comunidades atendidas pela escola de Nova Aurora, para construção do canteiro econômico é preciso, nessa ordem: i) o nivelamento do terreno, arrancando as raízes para não brotarem e furar a lona; ii) o levantamento de alvenaria na altura mínima de $30 \mathrm{~cm}$; iii) a forração com uma camada de aproximadamente $2 \mathrm{~cm}$ de areia; iv) colocação de lona plástica deixando uma saída para escoar a água no período de chuva; v) preparação da terra com adubo orgânico e um pouco de terra arenosa; e, vi) cultivo das hortaliças e legumes. Estes foram os passos que seguimos para construção do canteiro econômico na escola.

Como tínhamos que cavar um buraco de 1 metro de largura e 35 centímetros de profundidade, não foi possível levar as crianças para ver de perto estas etapas do canteiro, mas foi explicado em sala como aconteceu cada momento da preparação inicial do canteiro.

$\mathrm{Na}$ escola já havia alguns canteiros convencionais, assim mesmo, o diretor e supervisora aprovaram o projeto e logo disponibilizaram um espaço no fundo da escola, chamado de quintal e ali começamos nossos trabalhos de cavar o buraco. Toda a água que foi utilizada no canteiro vem da cisterna construída no fundo da escola, com capacidade de armazenar 52 mil litros de água, que serve como água potável e para regar as hortas cultivadas na escola. Os alunos trouxeram as sementes e plantaram cenoura, rúcula, alface e cebolinha.

\section{Estágio e pesquisa}


Diante da potencialidade das ações realizadas em estágio IV, a estagiária sentiu então a necessidade de que, como último percurso formativo, a temática do canteiro econômico no contexto do Estágio fosse foco de pesquisa. Para isso, sua monografia de conclusão de curso discutiu a experiência de construção de um canteiro econômico na Escola Estadual do Povoado de Nova Aurora no contexto de um projeto de intervenção do Estágio Supervisionado IV em Ciências da Natureza do curso de Licenciatura em Educação do Campo da UFTM.

Com este objetivo, trazemos aqui um recorte dos dados provenientes desta pesquisa realizada por meio de entrevistas semiestruturadas com a professora supervisora, direção e outros trabalhadores da escola, mediante um roteiro de questões. As interações verbais foram gravadas em áudio com a permissão dos entrevistados.

Assumimos a pesquisa qualitativa (YIN, 2016), pois essa nos proporciona apreender com profundidade a realidade experimentada de um determinado grupo social, no nosso caso a comunidade escolar, especialmente nas relações construídas com a experiência de construção do canteiro econômico durante as aulas de Ciências na Escola do Povoado de Nova Aurora.

Em seguida expomos a transcrição e análise de trechos das interações obtidas que mostraram de modo mais evidente como foi a experiência de construção do canteiro econômico, bem como sua importância para as aulas de ciências e para a escola. Adotamos nomes fictícios a fim de preservar a identidade dos sujeitos entrevistados e evitar possíveis constrangimentos futuros, especialmente quanto a posicionamentos mais críticos quanto às práticas, posturas e comportamentos adotados por membros da comunidade escolar, como também questionamentos ao sistema educacional.

\section{Discussão: entrevistas com a professora supervisora, direção e outros trabalhadores da escola}

A primeira entrevistada, Jacinta, professora atuante também na administração da escola, vive em uma comunidade do campo e ajuda seu companheiro no cultivo com o canteiro econômico que tem em sua casa. $A$ entrevista foi realizada em sua casa. 
Iniciamos a entrevista perguntando sobre a construção do canteiro econômico.

Pesquisadora: O que você achou da construção do canteiro econômico para a escola?

Jacinta: O que eu achei do canteiro sustentável na escola? Uma ideia legal sim, mas com as demandas educacionais, [...] alfabetização, o letramento, né... de tantas dificuldades e demandas, eu acredito que não veio a calhar, o servidor da educação, ele está sobrecarregado, e não consegue isso na nossa escola, né... a escola está arcando com a manutenção desse canteiro, o que acontece, o tempo é cronometrado do aluno, da escola, é uma realidade totalmente diferente de uma grande maioria, é uma escola do campo, que nem é considerada do campo, né... para o MEC e para o Estado, ela não é considerada do campo e ela está a $50 \mathrm{~km}$ do centro, né... e recebe filhos de agricultores familiares que já lida na casa, acontece, o servidor não vai lá molhar, os meninos já lida na casa, não tem uma matéria que correlaciona com isso, né... então, assim eu achei que foi interessante, é uma ideia bacana, mas não veio surtir um efeito na escola.

Para nossa primeira entrevistada, a construção do canteiro é um projeto que traz um ideal de sustentabilidade, percepção exibida pelo nome atribuído ao canteiro econômico: canteiro sustentável, mas nessa fala destaca principalmente as dificuldades da sua concretização: a sobrecarga de trabalho dos servidores da educação; o trabalho ("lida na casa") que os alunos já possuem; a falta de tempo na organização escolar reservado a projetos dessa natureza; e, a ausência de conteúdos curriculares que justifiquem a prática do canteiro. $\mathrm{Na}$ nossa visão, como mostraremos mais adiante a partir de outras entrevistas, pelo menos nesse último ponto, não há grandes dificuldades em relacionar conteúdos das Ciências com a construção do canteiro econômico. Práticas inerentes à vida no/do campo em escolas do campo também não deveriam estar restritas ao currículo oficial. Jacinta conclui dizendo que essa prática não surtiu efeito, não por negar sua importância ("é uma ideia bacana"), mas por esses impedimentos mais estruturais do sistema escolar.

Pesquisadora: Mas você pode perceber que este canteiro econômico traz algum aprendizado para a escola em geral? 
Jacinta: Na verdade qual é a lição que o canteiro deixou, eu acredito que deve ter alguma coisa que tem com relação no currículo, tem que ter uma relação, mesmo que vocês na Biologia, Ciências Biológicas, mas com o currículo em si, analisando o currículo de Minas Gerais, ou ainda não dá pra encaixar canteiro em questão de horário, né.. atividade prática, a escola não conseguiu ainda.

Pesquisadora: Você acha que na questão da água passou a ser visto pela comunidade escolar que o canteiro econômico realmente utiliza menos água?

Jacinta: Eu não consegui ver, porque na verdade eu [sou] do administrativo, não percebi.

Pesquisadora: Algumas contribuições para nossos próximos projetos?

Jacinta: Na verdade, o pessoal não está tendo consciência da necessidade, eles não conseguem, mesmo sendo uma comunidade tão precária, tão necessária e tão necessitada de água, ela não percebeu ainda, a necessidade de economizar, a necessidade do canteiro. Então, realmente o canteiro é uma ideia boa sim, deveria ser implantado na escola sim, mas infelizmente não surtiu efeito, parece que quem menos tem, quer mais desperdiçar.

Jacinta continua reafirmando sua posição de que a organização do tempo escolar, mencionando explicitamente o currículo, deveria proporcionar condições para o desenvolvimento de projetos como o do canteiro econômico. Sua fala também chama a atenção para o quanto o currículo escolar está distante da vida, da sua concretude e da comunidade em que a escola está inserida.

Também merece destaque o fato de que Jacinta deixa claro o lugar que ocupa e de onde enxerga o canteiro econômico: "Eu não consegui ver, porque na verdade eu [sou] do administrativo". Por fim, retoma, reformulando, a avaliação anterior e diz que o canteiro "deveria ser implantado na escola sim", apesar de mencionar outro impedimento que seria a falta de consciência das pessoas.

O segundo entrevistado, Antônio, trabalha como porteiro na escola, sempre morou na comunidade de Nova Aurora, atualmente vive em uma comunidade do campo em Fruta do Leite (MG), um de seus filhos estuda nessa mesma escola no qual Antônio trabalha. Começou a trabalhar na escola há cerca de 8 anos, mas antes trabalhou na sede do município, em Rio Pardo. 
Pesquisadora: O que Sr. achou desse canteiro econômico?

Antônio: Eu achei muito importante porque na economia de água foi bastante e até que produziu, né... eu olhei lá as plantas ficou bonita, né. Mesmo se passar dois ou três dias sem molhar, mas conserva, né.

Pesquisadora: O Sr. viu alguma contribuição do canteiro para a escola?

Antônio: Ajudou porque as meninas [cantineiras] sempre pega o cheiro verde pra usar na escola, né. Achei que foi uma contribuição muito boa.

Em contraste com a fala da primeira entrevistada, Antônio demonstra que observou de perto o desenvolvimento do canteiro econômico. Ele menciona tanto a economia de água, "Mesmo se passar dois ou três dias sem molhar, mas conserva, né", como a produção de hortaliças e legumes que podem ser utilizados na merenda escolar, a exemplo do cheiro verde. Em outras palavras, mesmo do lugar de porteiro que poderia indicar distanciamento do que acontece na escola como o desenvolvimento desse projeto, ele vê principalmente duas contribuições concretas: a economia de água e a produção de alimentos para a merenda escolar.

Pesquisadora: A gente viu que tem muitas dificuldades, né? $\mathrm{O}$ Sr. acha que tem algum ponto que poderia ser melhorado na construção do canteiro?

Antônio: Então, achei assim que a gente poderia aumentar mais os canteiros, ter mais parceria, né. Porque eu estou vendo que os funcionários não tá tendo contribuição de ajudar, é, assim, pra aumentar o trabalho, né. Se eles ajudar, é uma ajuda pra escola, uma coisa que a gente sabe que é natural, né... que a gente não está trazendo química, né. A gente produziu assim sem química, né.

Sobre as dificuldades, Antônio comenta da necessidade de construir mais canteiros, mas que isso implicaria obter mais ajuda da comunidade escolar, "porque eu estou vendo que os funcionários não tá tendo contribuição de ajudar, é, assim, pra aumentar o trabalho, né". Um ponto a se destacar nessa fala é quanto houve uma ligação do projeto com a vida do Sr. Antônio, porque sempre construiu horta na escola, mas não desse modelo de canteiro econômico. Ressalta que achou muito interessante, pois o foco desse canteiro é a economia de água e a produção de alimentos orgânicos e por sempre ter morado no campo 
nunca tinha visto ou ouvido falar de um canteiro desse modelo. Como ele mesmo destaca, com a construção desse canteiro e com a ajuda dos membros da escola, todos saberiam da procedência dos alimentos, pois o cultivo é também sem o uso de agrotóxicos ou produtos industrializados. E essa é mais uma observação da importância do canteiro, além da economia de água e ajuda na merenda escolar, observada pelo Sr. Antônio.

A terceira entrevistada, Luísa, tem formação superior em Ciências Biológicas e trabalha na escola como professora de Biologia e Ciências há onze meses (momento da realização da entrevista). A mesma foi supervisora da primeira autora deste artigo de estágio IV do curso Licenciatura em Educação do Campo da UFTM.

Pesquisadora: O que você achou desse canteiro econômico?

Luísa: Achei legal a ideia, foi produtivo, e assim pro lugar, eu achei interessante porque como aqui a água é bem escassa, contribui bastante, porque eu percebi sempre que as meninas da cantina molhavam lá o canteiro, ficava bastante dias molhado e úmido, e aí economizava água, né. Sem precisar gastar muita água.

Para a Luísa, a ideia do canteiro econômico surtiu efeito e menciona que foi produtivo, por ser um projeto que traz a economia de água para a comunidade local, na qual sofre bastante com a escassez da água, e não se toma muito tempo para manutenção, como exemplo, o regar do canteiro, houve dias de ficar sem molhar e mesmo assim o canteiro ainda assim continuava úmido. Isto é, a economia de água vem acompanhada na economia de tempo para sua manutenção.

$[\ldots]$

Pesquisadora: E quais são os principais ensinamentos e aprendizados que o canteiro econômico pode trazer para os alunos?

Luísa: Para os alunos, os alunos geralmente, tem como a maioria, são de zona rural, eles têm conhecimento, mas ou menos como que funciona um canteiro, né. Só que o canteiro econômico foi bom pra trabalhar alguns temas como a falta de água e como é importante economizar a água e sobre os alimentos também, né. Como que funciona alimentação saudável e tipos de nutrientes que pode conter em cada um dos 
alimentos e também como que eles tem afinidade com esse tema, mas muitos não sabem como fazer um canteiro, como que é preparar a terra pra fazer o canteiro, então eu acho que o canteiro foi interessante e deu pra eles aprenderem algumas coisas, como esses temas.

Por ser uma escola que atende a maioria de alunos que vem do campo temos a vantagem de muitos deles já conhecerem como se prepara ou cultiva um canteiro, então a participação se torna mais efetiva, pois há interesse pelo tema proposto em sala de aula e muitos são os ensinamentos que foram colocados dentro do tema canteiro econômico. Observa-se que o conhecimento se torna mais abrangente quando se estuda na prática a realidade vivida dos educandos e as aulas podem ser mais dinâmicas e interessantes tanto para os alunos como para os professores. Partiu-se de algo familiar para os alunos, desde a mobilização deles próprios no levantamento das mudas e sementes trazidas de casa para serem plantadas no canteiro, mas que não foi uma repetição do que já encontram em suas casas, introduziu-se a partir das aulas de Ciências uma novidade, a tecnologia social do canteiro de tipo econômico, ao mesmo tempo, que os conteúdos das Ciências eram contextualizados na prática. O canteiro econômico trouxe possibilidades de entender como podemos alimentar de forma saudável sem prejudicar o meio ambiente. $E$ isso poderia valer para a escola do campo ou da cidade. A fala de Luísa exibe muito bem essa perspectiva da nossa experiência que, para nossa satisfação, também é a dela.

Pesquisadora: Houve alguma dificuldade ou ponto que poderia ser melhorado na construção do canteiro econômico? Como na manutenção e participação dos alunos?

Luísa: Assim, eu acho que a principal dificuldade assim que teve é porque os alunos, a gente tem dificuldade de tirar eles da sala pra levar pra o desenvolvimento do canteiro, como a turma também é um pouco cheia, dificulta e os alunos têm que ter um acompanhante para ir levar e voltar pra sala, eu acho que essa foi uma dificuldade que eles deveriam ter acompanhado mais o desenvolvimento do canteiro e não teve muita oportunidade com as atividades que tem todos os dias de levar eles lá pra ver como que estava a horta, eu levei uma vez só depois que eles fizeram o canteiro, né. $E$ depois eles não viram mais assim, viu já estava nascido as coisas tudo, já tinha nascido, pois é tá bem bonito o canteiro, mas assim eles não viram depois que cresceram as coisas tudo, que cenoura por exemplo que plantei lá depois 
nasceu alguns pés, que inclusive foi uma aluna que trouxe a semente pra plantar lá.

Notamos que uma das maiores dificuldades de nós professores é a "retirada" dos alunos da sala de aula, pois estão acostumados a ficar o tempo todo dentro de sala de aula e quando precisam sair para realizar qualquer atividade fora da sala, precisam de mais pessoas para acompanhar, o que é difícil, pensando que a maioria das aulas, o professor pode contar apenas com ele mesmo. Assim mesmo, Luísa diz da grande potencialidade do canteiro, possivelmente se os alunos tivessem acompanhado em mais momentos seu desenvolvimento, o resultado seria ainda mais proveitoso. Inclusive, ela menciona uma interação espontânea, sem nosso planejamento prévio, de uma aluna que trouxe sementes de cenouras para serem plantadas lá. Ou seja, o canteiro econômico não é uma prática fechada em si mesmo, ele tem várias aberturas para interações e engajamentos diferentes. A conscientização e o aprendizado tornam os alunos coparticipantes, autônomos.

Pesquisadora: Quais são as possibilidades da construção do canteiro econômico presente na inserção dos conceitos de Ciências?

Luísa: É a inserção do tema canteiro econômico nos conteúdos de Ciências, é na turma que a gente fez os alunos, eles já viram este conteúdo na série anterior que é no $6^{\circ}$ ano, eles veem o tema alimentação, eles veem os nutrientes, a quantidade de nutrientes que tem cada alimentação e aí tipo assim no $7^{\circ}$ ano, a gente trabalhou mais as questões dos nutrientes mais como uma revisão dos conteúdos, pra eles relembrar tudo que eles já viram. Eu acho, inclusive, interessante, isso às vezes os alunos ver um conteúdo e nem sempre eles aprendem, né. E aí quando a gente trabalhou sobre o canteiro econômico, eu aproveitei pra falar de algumas coisas que eles já tinham visto e esse negócio da preparação do solo é um tema que eles já viram no $6^{\circ}$ ano e aí a gente aproveita pra fazer uma revisão pra ver se realmente eles aprenderam, se eles têm alguma afinidade com o tema e também vai tá vendo na prática, porque geralmente eles veem na sala de aula, mas não sabe como que funciona na prática, né. A questão do solo, a questão dos nutrientes e então o canteiro econômico foi bom pra gente trabalhar estes temas que eles já tinham visto.

Podemos perceber pela fala da professora Luísa que o projeto de construção do canteiro econômico tem forte relação com os conteúdos do Ensino de Ciências em diferentes anos do Ensino Fundamental. Percebemos também 
o quão importante é revisitar aquilo que os alunos já tinham estudado no ano anterior, muitos são os conteúdos que podem ser contemplados. Um ponto que podemos destacar em sua fala é que há conteúdos estudados que os alunos acabam não aprendendo por falta da prática, mas em compensação, quando se tem algo para estudar mais de perto, vemos que o aluno se interessa mais pelos conteúdos e muitas são as perguntas e questionamentos. E a questão é o que ensinamos somente na teoria muitas das vezes passam coisas despercebidas e na prática não, pois cada detalhe é um questionamento e aprendizado, porque o aluno pode tocar, sentir, ter uma visão ampliada, isso é muito gratificante tanto para o aluno como para o professor.

A questão da água foi muito discutida dentro da construção do canteiro econômico sendo que o nosso maior objetivo foi o de mostrar na intervenção como se pode economizar água para o cultivo de alimentos, por ver que é uma realidade de escassez de água, além disso o projeto tentou ser um incentivo para que essa prática chegasse nas famílias dos alunos. Luísa comenta que mais pessoas deveriam ter tido o conhecimento do que estava sendo desenvolvido ali, a inovação do canteiro econômico. Ela ainda diz que essa prática deveria ser trabalhada também fora da disciplina de Ciência, o que mostra seu potencial para práticas interdisciplinares e comunitárias que envolvam escola e comunidade.

O quarto e último entrevistado, Alfredo, é diretor da escola Estadual do Povoado de Nova Aurora, mas antes tinha como função a vice direção. Ele tem 32 anos, com 8 anos de profissão docente, já trabalhou em escola particular, estadual e municipal. Antes de diretor, atuava como professor de História e Artes.

Pesquisadora: O que você achou da construção deste canteiro econômico?

Alfredo: Eu acho que na verdade é uma iniciativa boa para que os alunos em si, é bom que eles aprendem, porque a gente tem condição de fazer, mas acha muito difícil, na verdade não é muito difícil, é fácil, né. Essa que é a verdade, a gente não sabe é fazer, quando ensina, né.... principalmente os alunos, talvez eles levem essa ideia para os pais.

Pesquisadora: Você vê que teve alguma contribuição para escola? 
Alfredo: Teve as meninas [cantineiras] está colhendo coisa lá já, tá colhendo muita coisa pra escola, ou seja, na própria alimentação, já tá tendo benefícios, sem falar no conhecimento que trouxe para os alunos.

Alfredo começa dizendo que foi uma iniciativa boa e que os alunos podem aprender na prática com desenvolvimento do canteiro econômico, práticas estas que podem ser desenvolvidas nas casas de suas famílias. Segundo ele, são possibilidades de ensino que podem parecer difíceis em um primeiro momento, mas que se aprende fácil. Fala também que "os alunos, talvez eles levem essa ideia para os pais", isso é possível sim graças aos ensinamentos trazidos de suas comunidades pelos alunos que podem ser incorporados às realidades escolares dos mesmos.

Pesquisadora: Você viu se teve algum ensinamento e aprendizado para os alunos?

Alfredo: Eu acredito que sim, principalmente para as turmas que foi mais trabalhado, eles tiveram este contato, né. Com esse contato eu acredito que eles aprenderam e visto que o projeto continua, né. Então nós pretendemos, que tem um grupo aí que está com o projeto, continuar este projeto de meio ambiente e vai envolver toda comunidade, então aproveita e leva para todos.

Alfredo confirma que houve uma conscientização, especialmente das turmas envolvidas com o projeto. Há a intenção da escola em continuar com os projetos abrangendo assim toda a comunidade escolar, no qual cada vez mais pessoas possam se engajar no desenvolvimento desse tipo de prática como a construção de novos canteiros, a reutilização de materiais para ornamentação e reciclagem, feira de ciências, por exemplo, onde os alunos apresentam produtos produzidos por eles mesmos em suas casas e comunidades, entre outros.

Percebemos que nem todos os entrevistados são unânimes quanto aos efeitos positivos do projeto de intervenção na escola. Uma das entrevistadas fala, inclusive, que o tema canteiro econômico é importante, mas há limitações na organização da escola, do currículo e dos tempos dos profissionais da escola que impediram a efetivação do projeto. Entendemos que essa ideia está em contraste em relação as outras falas dos outros entrevistados, pois eles veem o canteiro econômico como forma de conscientização sobre a escassez e uso 
consciente da água, de diminuição do tempo de trabalho para seu manejo, da produção de alimentos saudáveis e na articulação com conceitos das Ciências como muito bem explicitado pela professora de Ciências.

\section{Considerações finais}

O estágio com e como pesquisa permitem o estagiário considerar-se como parte de um coletivo de formação possibilitando-o desenvolver ações que dão sentido ao lugar e aos sujeitos envolvidos, concretiza aprendizados e mobilizam atitudes (PIMENTA; LIMA, 2012). Nesta experiência em particular, possibilitou o avanço da construção da identidade e profissionalização docente do/no/para o contexto do campo da primeira autora, aspecto que por si só poderia ser analisado.

A proposta de inserir a tecnologia social do canteiro econômico no estágio nasceu a fim de proporcionar aos alunos o conhecimento e a divulgação dos seus costumes no âmbito escolar de uma forma diferente daquela executada por eles em suas comunidades e casas, pois muitos dos alunos nem sequer sabiam que existia o canteiro econômico. O canteiro proporcionou uma aprendizagem de conteúdos das Ciências na prática, sendo uma alternativa de aprendizado, "contribuindo para ampliar a herança cultural, além de [...] uma apreensão qualitativamente superior em relação [...] à própria realidade" (PIMENTA; LIMA, 2012, p. 234).

A questão de escolha do tema do projeto também foi com a intenção de mostrar aos alunos os diversos benefícios para as famílias dos alunos e não alunos da escola, como diversificar a produção agrícola, melhorar a alimentação e a renda familiar, além de estimular a relação entre os agricultores familiares e o mercado da região, para produção de alimentos saudáveis e ecologicamente corretos. Quanto ao projeto, no seu planejamento e execução, não encontramos maiores dificuldades, pois tanto a professora supervisora do estágio, direção e outros trabalhadores da escola contribuíram bastante para que o projeto tivesse um resultado adequado.

O canteiro econômico levanta a questão do uso e conservação da água, o cultivo de alimentos sem uso de venenos, práticas agroecológicas, dentre 
outras, práticas que estão presentes na vida do campo, como nessas comunidades atendidas pela escola de Nova Aurora, e que em muitos casos não encontramos nos livros didáticos, como também estão ausentes no currículo de Ciências da Natureza.

Em geral, não vemos as realidades vividas pelos alunos desta escola sendo incluídas no seu currículo escolar e por ser uma escola que atende $99 \%$ de alunos que vem das comunidades rurais, observado desde a época de estudante até em os estágios obrigatórios realizados pela primeira autora neste contexto escolar, a distância dos conteúdos da vida do campo. Por mais que a escola, formalmente, não seja reconhecida como uma escola do campo, nós trabalhadores da educação devemos lutar por incluir na escola práticas e modelos de ensino que incentivem uma educação no/do campo, onde a realidade vivida pelos alunos seja ensinada dentro de sala de aula como um aprendizado e uma cultura da comunidade escolar, não desvalorizando os outros conhecimentos escolares e das Ciências, mas promovendo uma integração de saberes, na qual os conhecimentos tradicional e científico possam ser visto como complementares.

Ainda é um grande desafio pensar em uma escola que adote o movimento pedagógico descrito por Caldart (2011). A escola observada, como tantas outras que são reconhecidas formalmente ou não como do campo (estão em área rurais e/ou atendem alunos do campo), carecem de práticas pedagógicas coerentes com a vida no/do campo, especialmente quando pensamos na área de conhecimento das Ciências da Natureza. Assim, acreditamos que o projeto de intervenção do canteiro econômico configurou-se como uma importante contribuição para apontar que é possível uma aula de ciências, uma escola, um ensino que não fique aprisionado nas grades curriculares porque

Escola é lugar de estudo, porque é lugar de formação humana, e não o contrário. Se isto está claro, passamos a ter outras referências para planejar nossas aulas, orientar pesquisas, produzir conhecimento. (CALDART, 2011, p. 119 e 120).

\section{Referências}

AMARAL, A. Q.; JUNIOR, É.J.H.; SADRAQUE, C.; MIGUEL, K.; LARA, J.G. A implantação de horta orgânica como instrumento para a formação de alunos 
participativos. In: Seminário Internacional "Experiências de Agenda 21: os desafios do nosso tempo, 2009, Ponta Grossa (PR). Anais. Ponta Grossa: Agenda 21 Paraná, 2009.v. 21, Ponta Grossa- PR- Brasil, 2009.

ASSAI, N. D. de S.; BROIETTI, F. C. D.; ARRUDA, S. de M.. O estágio supervisionado na formação inicial de professores: estado da arte das pesquisas nacionais da área de Ensino de Ciências. Educação em Revista, Belo Horizonte, v. 34, e203517, 2018.

CREPALDE, R. S., KLEPKA, V., HALLEY, T.O.P.; SOUSA, M. A integração de saberes e as marcas dos conhecimentos tradicionais: reconhecer para afirmar trocas interculturais no ensino de ciências. Revista Brasileira de Pesquisa em Educação em Ciências, 19, p. 275-297, 2019.

OVIGLI, D.F.B.; KLEPKA, V. A formação de professores em Ciências e Matemática na Educação do Campo a partir das experiências em estágios e TCCs. Revista Contexto \& Educação, 2020, no prelo.

BRASIL, Conselho Nacional de Educação. Resolução CNE/CP, no. 2 de 1 de julho de 2015. Diretrizes Curriculares Nacionais para a formação inicial em nível superior (cursos de licenciatura, cursos de formação pedagógica para graduados e cursos de segunda licenciatura) e para a formação continuada. Brasília, DF, 2015. Disponível em: $<$ http://portal.mec.gov.br/docman/agosto-2017-pdf/70431-res-cne-cp-00203072015-pdf/file >. Acesso em: 22 mai. 2019.

BRITO, I. C. A. Geraizeiros em movimento. In: COSTA, J. B. A; OLIVEIRA, C. L. (orgs.). Cerrados, Gerais, Sertão: comunidades tradicionais nos sertões roseanos. São Paulo: Intermeios, 2012.

CALDART, R. S. A Escola do Campo em Movimento. In: ARROYO, M.G.; CALDART, R.S.; MOLINA, M.C. (orgs). Por uma educação no campo. Petrópolis: Vozes, 2011.

IBGE (Instituto Brasileiro de Geografia e Estatística). Cidades: Rio Pardo de Minas. Disponível em: https://cidades.ibge.gov.br/brasil/mg/rio-pardo-deminas/panorama.Acesso em: 18.05.2020.

LEITE, S. F. Diagnóstico participativo em assentamento rural e avaliação da tecnologia social canteiro econômico. 2017. 102 f. Dissertação (Mestrado em Recursos Naturais), Programa de Pós-graduação em Recursos Naturais, Centro de Tecnologia e Recursos Naturais, Universidade Federal de Campina Grande - Paraíba - Brasil, 2017.

PIMENTA, S. R; LIMA, M. S. L. Estágio e Docência. $7^{a}$ ed. São Paulo: Cortez, 2012.

SEMEAR INTERNACIONAL. Canteiros econômicos e reuso de água cinza com filtro biológico. Disponível em: http://portalsemear.org.br/boaspraticas/canteiros-economicos-e-reuso-de-aguacinza-com-filtro-biologico/. Acesso em: 18/05/2020. 
SILVA, C.E.M.; PORTO-GONÇALVES, C.W.P. Água, Cerrado, eucalipto e gente. Belo Horizonte: Jornal Estado de Minas, Caderno Agropecuário, janeiro de 2004, p. 2-12.

UFTM, Universidade Federal do Triângulo Mineiro. Projeto Pedagógico do Curso de Licenciatura em Educação do Campo. 2019.

YIN, R. K. Pesquisa qualitativa: do início ao fim. Porto Alegre: Bookman, 2016.

\section{Sobre os Autores}

\section{Graciene Ferreira de Oliveira}

graciene.oliveira.uftm.2016@gmail.com

Possui graduação em Licenciatura em Educação do Campo, área de conhecimento Ciências da Natureza, pela Universidade Federal do Triângulo Mineiro (2020). Tem experiência na área de Educação, com ênfase em EnsinoAprendizagem.

\section{Rodrigo dos Santos Crepalde}

rodrigocrepalde@gmail.com

Professor da Universidade Federal do Triângulo Mineiro (UFTM), Doutor em Educação, atua no curso de Licenciatura em Educação do Campo e no Programa de Pós-Graduação em Educação em Ciências e Matemática (PPGECM) da UFTM e é membro do grupo de pesquisa Integração de Saberes na Formação de Professores de Ciências para o Campo.

\section{Verônica Klepka}

veronicaklepka@gmail.com

Possui Licenciatura em Ciências/Biologia (2008), Especializações em Meio Ambiente e Recursos Hídricos (2009) e Metodologia do Ensino Superior (2011), Mestrado (2014) e Doutorado (2017) em Educação para a Ciência e o Ensino de Matemática pela Universidade Estadual de Maringá (UEM). Atualmente é professora Adjunta da Universidade Federal do Triângulo Mineiro (UFTM), na área de Ciências da Natureza, Curso de Licenciatura em Educação do Campo, atuando também como coordenadora e professora do Programa de Pós Graduação em Educação em Ciências e Matemática (PPGECM/UFTM). Tem experiência na área de Ensino de Ciências, atuando principalmente na Formação de Professores de Ciências. Participa do grupo de estudos e pesquisas da UFTM: Integração de Saberes na Formação de Professores de Ciências para o Campo. 